\title{
SPECIES DIVERSITY OF THE EPIBENTHOS IN A HIGHLY DISTURBED CORAL REEF COMMUNITY IN THE PHILIPPINES
}

\author{
by \\ EDGARDO D. GOMEZ ${ }^{1)}$
}

\begin{abstract}
Baseline studies on the marine benthic communities around the proposed site of the first nuclear power plant in the Philippines have indicated a highly disturbed coral reef community. The areas studied are all subtidal, mostly starting just below the littoral and having an average depth of five meters. The study consisted in taking a census with SCUBA of the epibiota in quadrats on transects laid out perpendicular to the shoreline.

Results of the sampling during the dry season indicate a predominantly algal (Padina) community of low species diversity. Many of the conspicuous components of Philippine coral reefs are either absent or are present only in small numbers, e.g., hard and soft corals, crinoids, tridacnids, and colorful serpulids. Dynamite fishing is no doubt a major factor responsible for the condition of the dead reefs. Weather and erosion of the land areas with the resulting siltation have probably contributed to the poor condition of the reef communities as well.
\end{abstract}

\section{INTRODUCTION}

As one alternative to the dependence on oil for energy, the Philippines has decided to establish a nuclear power plant in the province of Bataan (Fig. 1). Preliminary to the construction of the unit, an environmental impact assessment is to be made. In line with this requirement, the present study was conducted to survey the shallow subtidal benthos as one component of a larger undertaking to establish baseline data on the total biotic composition of the environs of the proposed plant site. This study was conducted during the dry season, between March 20 and May 15, 1976.

\section{MATERIALS AND METHODS}

In addition to standard SCUBA diving equipment, the survey required the use of underwater writing slates (FAGER et al. 1966), a 50 m nylon transect line marked at one meter intervals, and a metal quadrat $50 \mathrm{~cm}$ by $100 \mathrm{~cm}$ in size.

1). Marine Science Center, University of the Philippines, Diliman, Quezon City, Philippines. 
EDGARDO D. GOMEZ

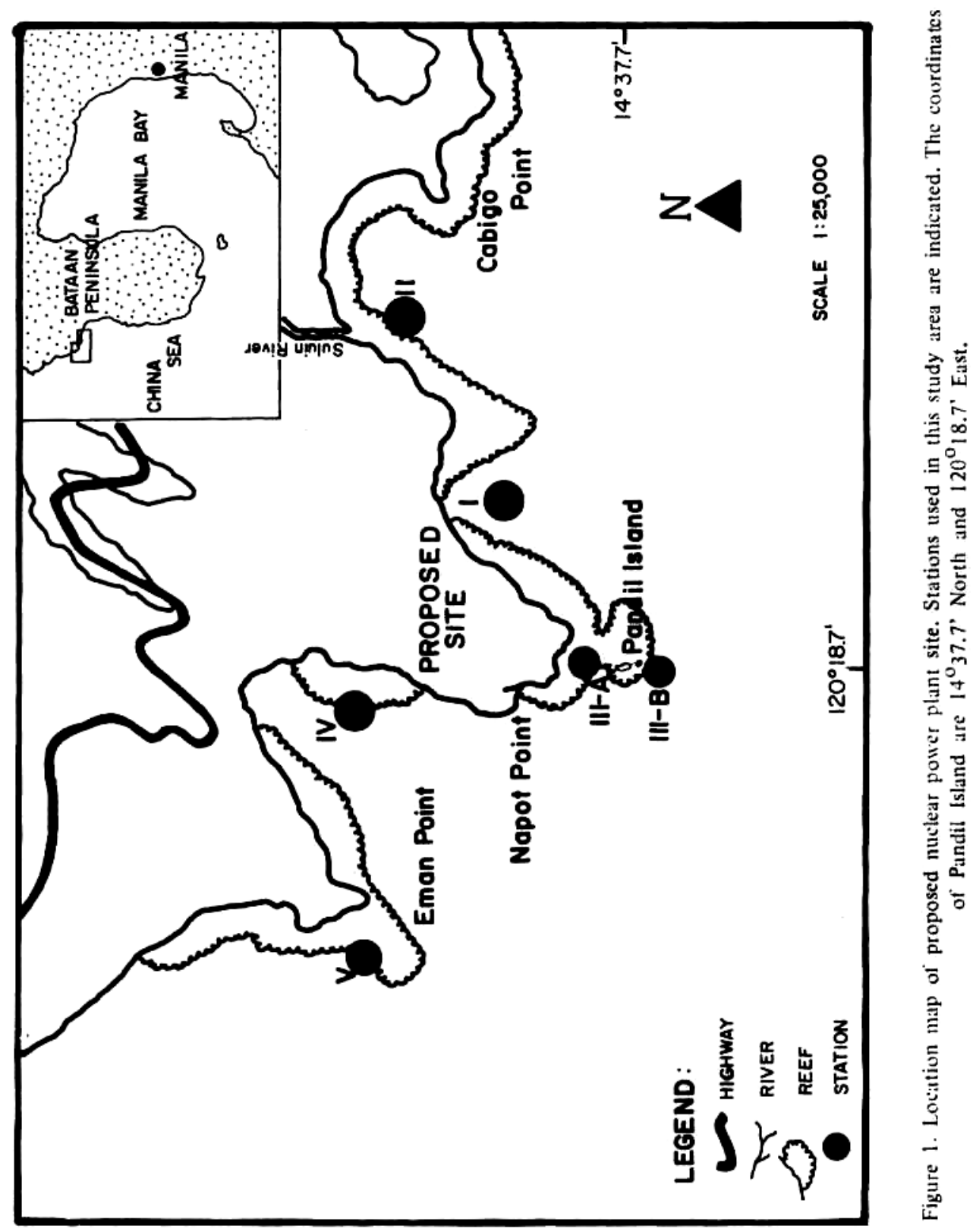




\section{SPECIES DIVERSITY OF THE EPIBENTHOS}

The subtidal benthic studies were conducted generally over hard substrates, i.e., over reef areas. There were five stations for this study, designated as Stations I, II, III, IV, and V (Fig. 1).

SCUBA was used for all the field surveys. Recording was done with the use of underwater writing slates while collecting was done with the use of nylon and plastic bags.

Systematic sampling was accomplished with a transect/quadrat method. At each station two $50 \mathrm{~m}$ transect were laid out perpendicular to shore and parallel to each other but separated by a distance of $10 \mathrm{~m}$. Transects were arbitrarily designated as "A" or "B". These transects were essentially extensions of the intertidal transects covered by another study. The shoreward (head) end of each transect was usually at a depth of $3 \mathrm{~m}$ and the tail end at $5 \mathrm{~m}$. An exception to this arrangement was Transect B of Station III, which transect was placed tandem to Transect A and located a distance offshore at a starting depth of about $8 \mathrm{~m}$ and ending at a depth of about $15 \mathrm{~m}$.

At five meter intervals along the length of each transect, quadrats were placed alternating on either side of the line. Each quadrat extended $50 \mathrm{~cm}$ along the transect and extended $100 \mathrm{~cm}$ perpendicular to the line, giving an area of $1 / 2 \mathrm{~m}^{2}$.

Within each quadrat the nature of the substrate and the depth were noted. Next, all the algae were identified, counted, and recorded. Where it was difficult to distinguish individuals in a bunch, each bunch was regarded as one count. In cases where identification was not possible in the field, the specimens were collected for laboratory identification. The process was repeated for the macrofauna. Besides the exposed invertebrates loose rocks were overturned in search for specimens. Whenever possible, coral rocks were split with the aid of a diver's knife. Coral rubble and sand were raked with gloved fingers.

From the quantitative data gathered various indices were calculated. These useful indices of species structure in communities were developed by various authors and coveniently tabulated by ODUM (1971) and briefly described below.

To compare stations, the index of similarity (S) between two samples was used. The formula is:

$$
S=\frac{2 C}{A+B}
$$

where $\mathrm{A}$ and $\mathrm{B}=$ number of species in sample $\mathrm{A}$ and $\mathrm{B}$ respectively;

$\mathrm{C}=$ number of species common to both samples 
To determine characteristics of dominance, the following index (c) was used:

$$
\mathrm{c} \quad=\quad \Sigma\left(\frac{\mathrm{ni}}{\mathrm{N}}\right)^{2}
$$

where $\quad$ ni $=$ number of individuals per species

(importance value)

$\mathrm{N}=$ total number of individuals (total of importance values)

Indices of diversity were computed according to the following formulae:

1) Species richness or variety indices (d) -

$$
d_{1}=\frac{S-1}{\ln N} ; d_{2}=\frac{S}{\sqrt{ } N}
$$

where $\mathrm{S}=$ number of species

$\mathrm{N}=$ total number of individuals

2) Evenness index (e) -

$$
\mathrm{e}=\frac{\mathrm{H}}{\ln \mathrm{S}}
$$

where $\quad \mathrm{H}=$ Shannon Index (see below)

$\mathrm{S}=$ number of species

3) Shannon index of general diversity $(\mathrm{H})-$

$$
\begin{aligned}
& \mathrm{H}=-\Sigma\left(\frac{\mathrm{ni}}{\mathrm{N}}\right) \ln \left(\frac{\mathrm{ni}}{\mathrm{N}}\right) \\
& \text { where } \quad \mathrm{ni}=\text { number of individuals per species } \\
& \mathrm{N}=\text { total number of individuals }
\end{aligned}
$$

\section{RESULTS}

Because the two transects of Station III proved to be quite different from each other, they are treated individually in much of this paper. Two separate tables (I and II) present the number of species of each taxon per station. The percentage of species contributed by each taxon is given for the 
SPECIES DIVERSITY OF THE EPIBENTHOS

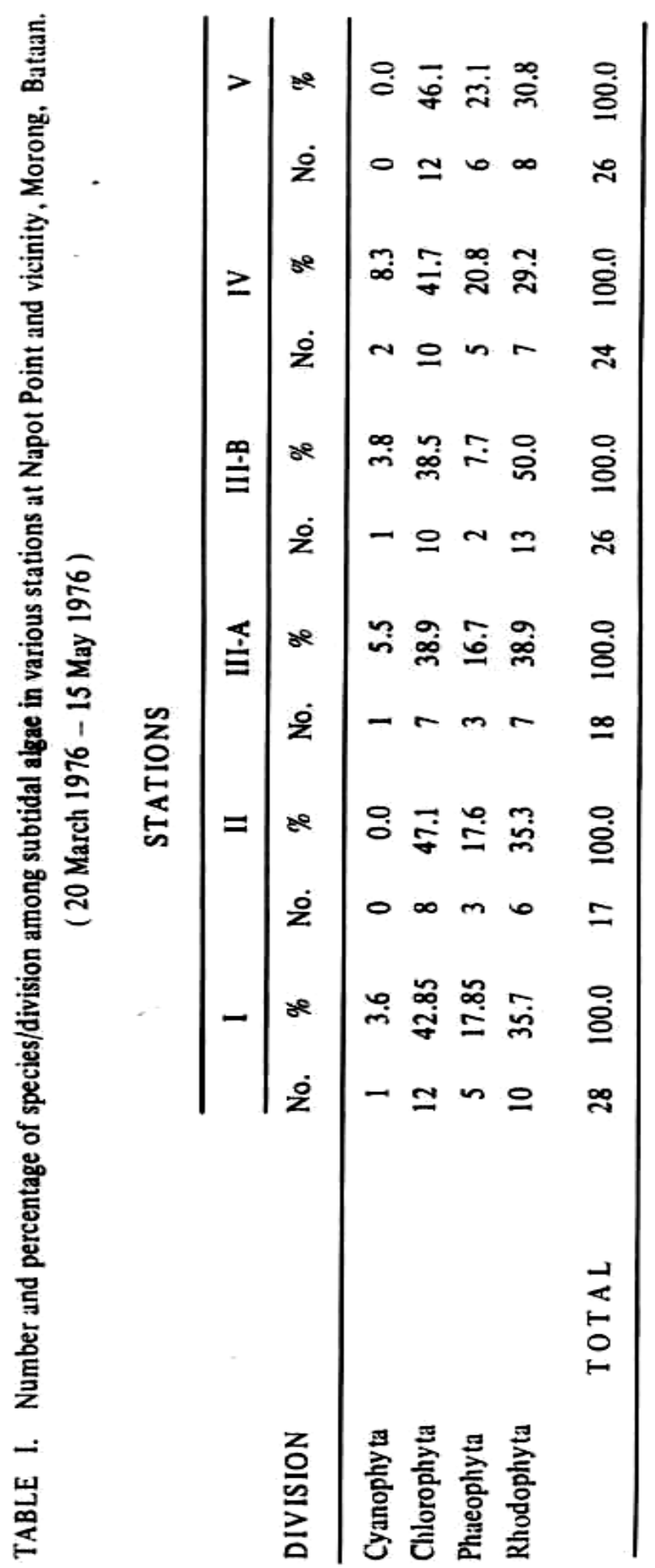


Edgardo D. Gomez

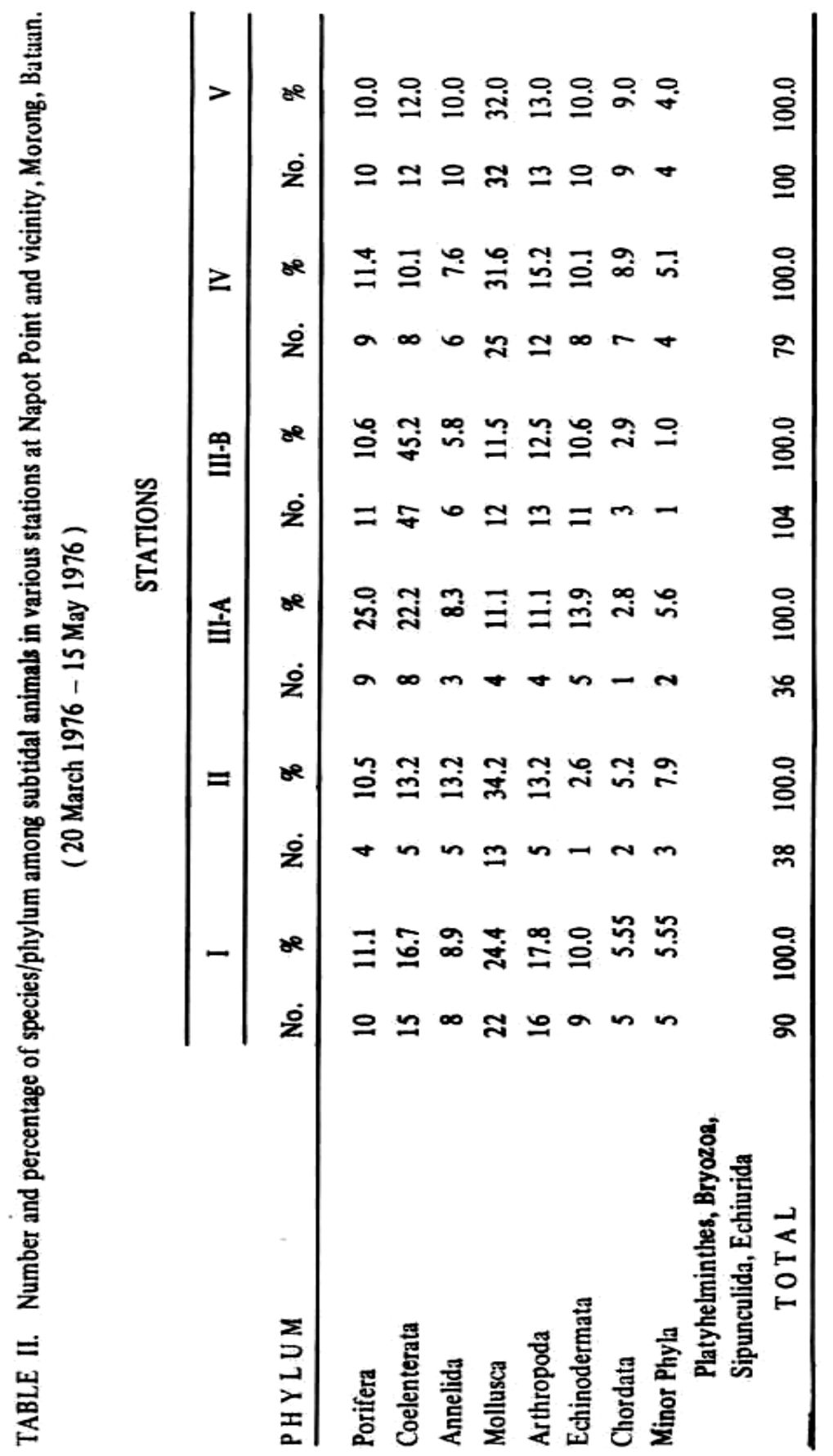




\section{SPECIES DIVERSITY OF THE EPIBENTHOS}

plants as well as for the animals except that four minor phyla were grouped as one for the latter (Table II). These results are presented graphically in histograms (Figs. 2A and 2B).

The areas studied represent shallow water, hard bottom communities. The substrate consists of a gently sloping platform reef, made up of calcareous material overlying volcanic rock, probably volcanic tuff. There is relatively little live coral on these shallow platforms. The average size of the encrusting forms (Porites spp.) is that of a man's large toenail while the branching forms (Pocillopora spp.) seldom become larger than a clenched fist. Since the invertebrates are not conspicuously dominant, these reef areas may better be referred to as algal communities. At the time of the sampling period, the most common alga was Padina japonica YAMADA, being present in great numbers. Along with it were Galaxaura oblongata (ELLIS \& SOlANDER ) LAMOUROUX, Dictyota dichotoma (HUDSON) LAMOUROUX, and Amphiroa fragilissima (L.) LAMOUROUX. Of the latter three, Galaxaura was the most conspicuous in terms of numbers and biomass. Hence, one might refer to the communities as Padina-Galaxaura communities, with the qualification that their appearance is seasonal.

These stations appear to be disturbed communities in an early successional stage of growth. An exception to the general condition described above is Station III-B, the deep transect on the edge of the reef formations. This station is intermediate between an algae and a true coral community. While algae were present in significant quantities, corals were relatively abundant without entirely covering the substratum. This station may be considered as a living coral reef community, probably second growth rather than primary. The discontinuities among the corals indicate a subclimax community as opposed to a pristine reef.

The results of the calculations for the various indices are tabulated. Table III gives the Index of Similarity results, Table IV the Index of Dominance, and Table $\mathrm{V}$ the various indices of diversity. In addition, Evenness and Dominance results are graphed in Figure 3 while those of the diversity indices are shown in Figures 4 and 5.

\section{DISCUSSION}

Station II, the easternmost study area, was located in a silty area near a river mouth. The estuarine condition will help explain apparent low species richness for this station (ODUM 1971). Station III also deserves special attention. Transect A was located on a wide reef flat between Napot Point and Pandil Island and had no apparent slope. This flatness may explain the 


\section{Edgardo D. Gomez}

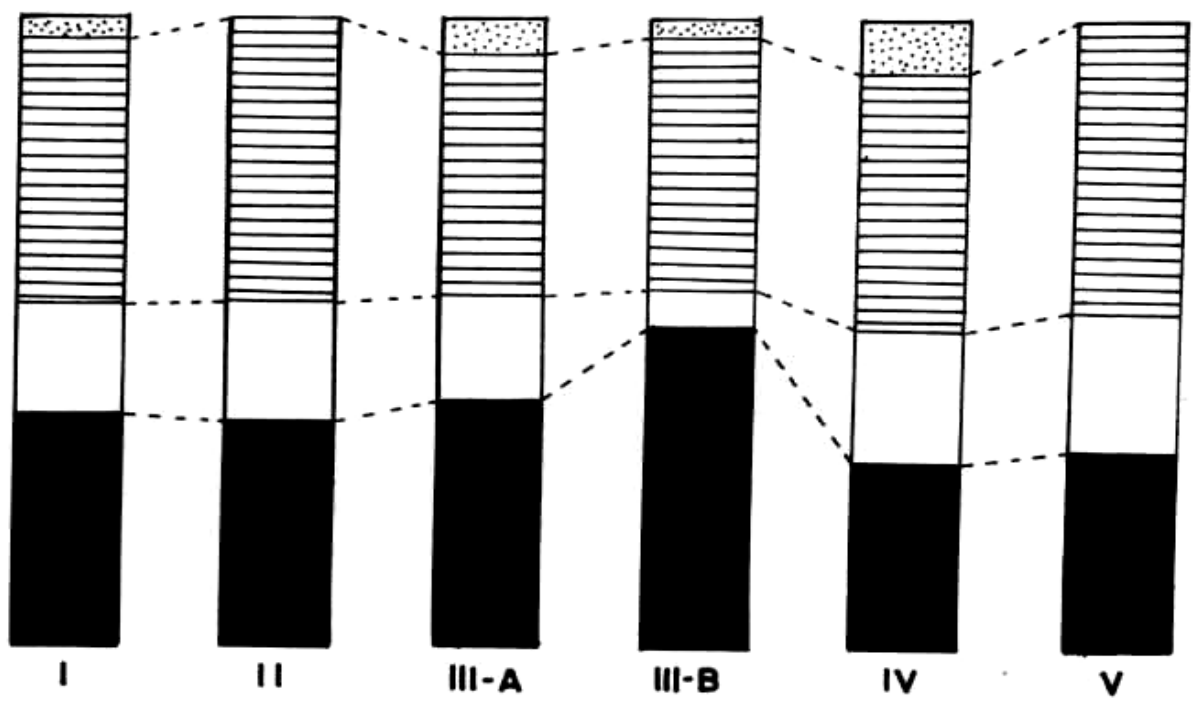

LEGEND:

$\because \because$

CYANQPHYTA
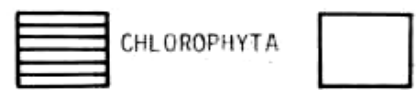

PHAE OPHYTA

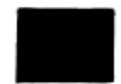

RHO DHOHYTA

Figure 2A. Percentage of species/division among subtidal algae by station. 
SPECIES DIVERSITY OF THE EPIBENTHOS
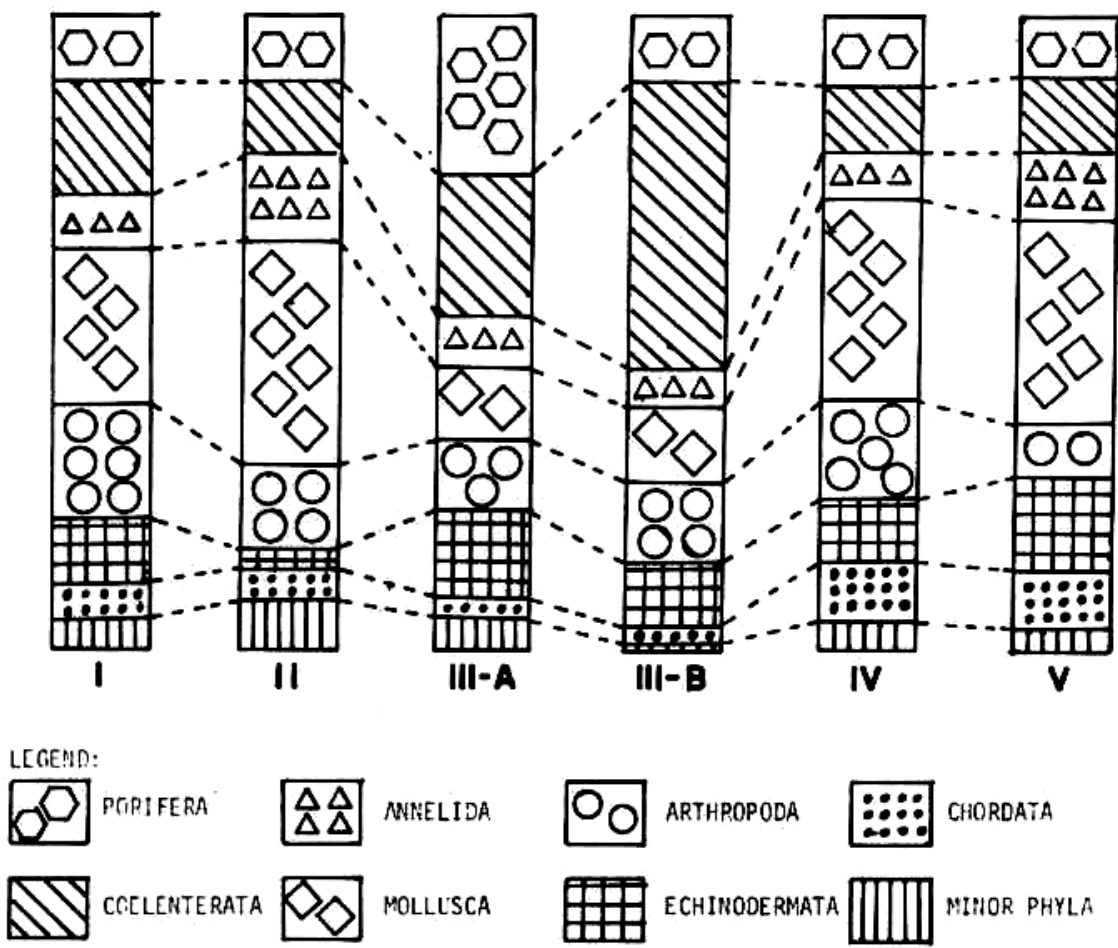

Figure 2B. Percentage of species/phylum among subtidal animals by station. 
EDGARDO D. GOMEZ

TABLE III. Index of similarity between two stations among various stations, Napot Point and vicinitv. Morong, Bataan.

\begin{tabular}{llllll} 
& \multicolumn{5}{c}{ S T A T IO N S } \\
\cline { 2 - 6 } S T A T I O N & I & II & III-A & III-B & IV \\
\hline II & 0.40 & & & & \\
III-A & 0.37 & 0.33 & & & \\
III-B & 0.31 & 0.18 & 0.28 & & \\
IV & 0.42 & 0.39 & 0.41 & 0.28 & 0.37 \\
V & 0.39 & 0.29 & 0.28 & 0.21 & \\
\hline
\end{tabular}

low species diversity of this transect. All the other transects had an incline, however slight. Transect B of Station III was the deep transect and actually represents a living coral reef by contrast.

The communities as a whole may be regarded as young and marginal with the exception of Station III-B. As previously stated, the communities may be regarded primarily as algal communities with the brown Padina japonica being dominant in numbers and probably biomass. The seasonality of various algal populations especially with respect to rainfall is well-known. AlCALA (1973) among others recognized this phenomenon in his study of algal communities in central Philippines. Two red algae, Galaxaura oblongata and Amphiroa fragilissima, a second brown Dictyota dichotoma, and two greens Bornetcllanitida (HARVEY) MUNIER-CHAlmAs and Neomeris vanbossae HowE were present at all stations. By contrast, only two animal species, the corals Porites cumidatus NEMENZO and P. quelchi STUDER were found in all stations, although two species of echinoids, Echinometra oblonga DE BLAINVILLE and Diadema setosum (LESKE), an orange sponge, a tubeworm, and a burrowing shrimp were found in nearly every transect although in relatively small numbers.

The distribution of species among the algae is fairly proportional among the stations if the blue-greens are not considered. This distribution showing a predominance of the green algae indicates suboptimal conditions for the growth of the browns and reds. It is interesting to note that the percentage distribution among all the stations, save one, parallel the species distribution of littoral algae in the stressed or polluted waters of Orion and Limay, Bataan recorded by VELASQUEZ et al (1971) and quoted by ALCALA (1973). 
SPECIES DIVERSITY OF THE EPIBENTHOS

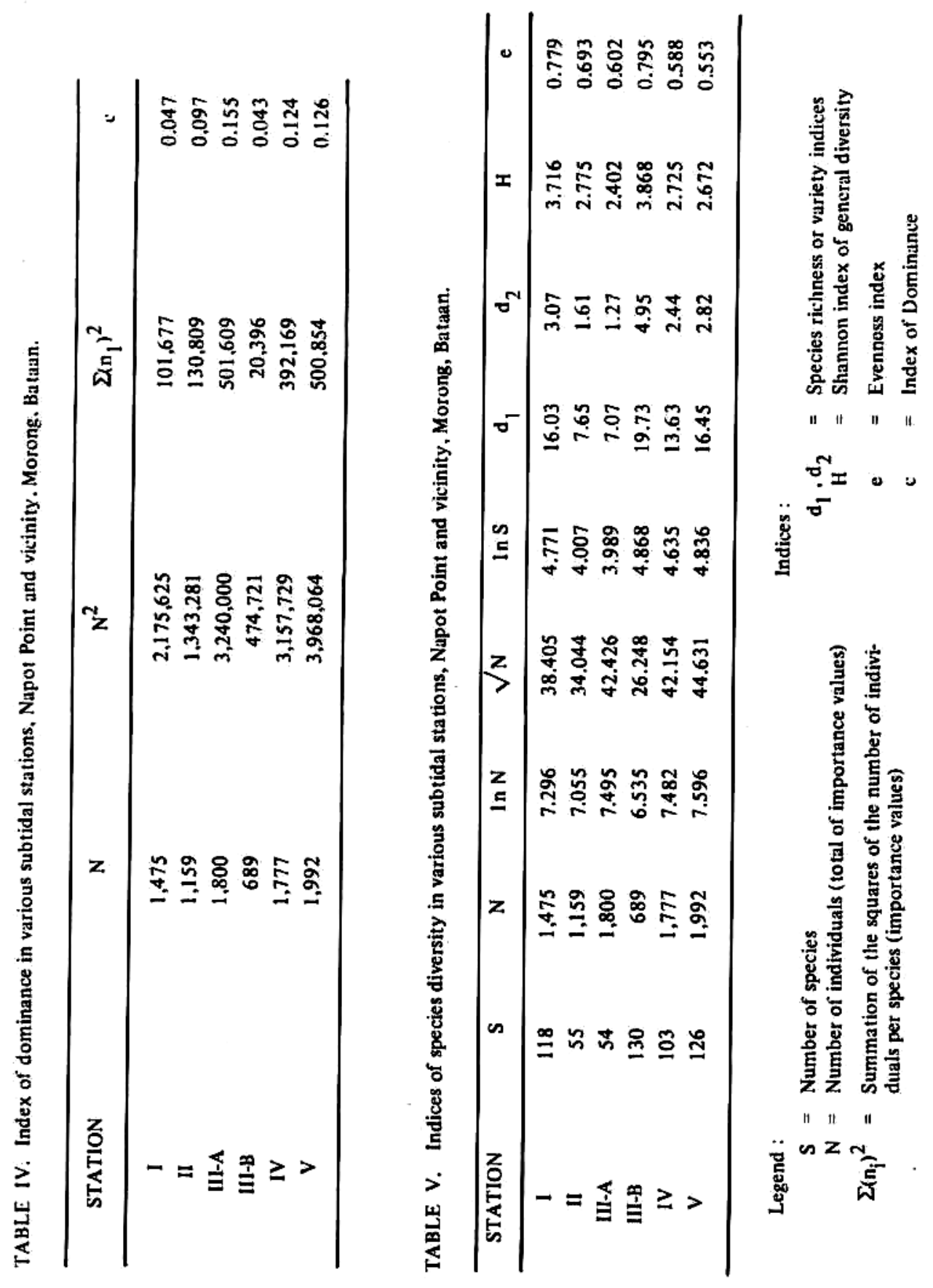




\section{EDGARDO D. GOMEZ}

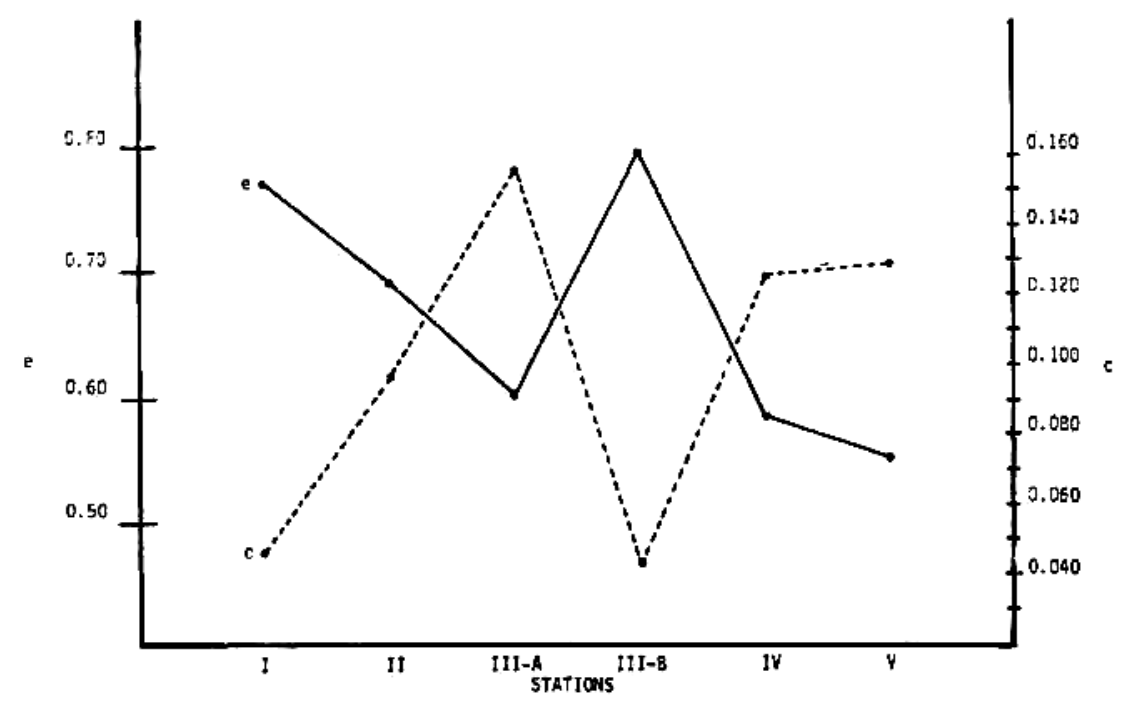

Figure 3. Graphs of Indices of Evenness (e) and Dominance (c) in various sub tidal stations at Napot Point and vicinity, Morong, Bataan.

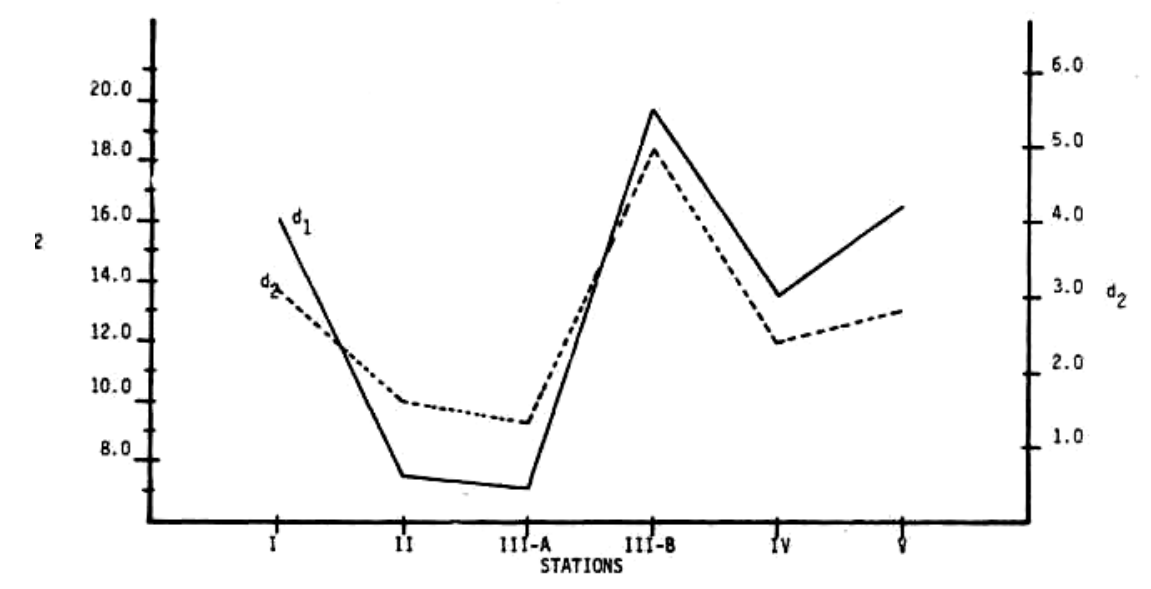

Figure 4. Species richness or variety indices of various subtidal stations at Napot Point and vicinity, Morong, Bataan. 
SPECIES DIVERSITY OF THE EPIBENTHOS

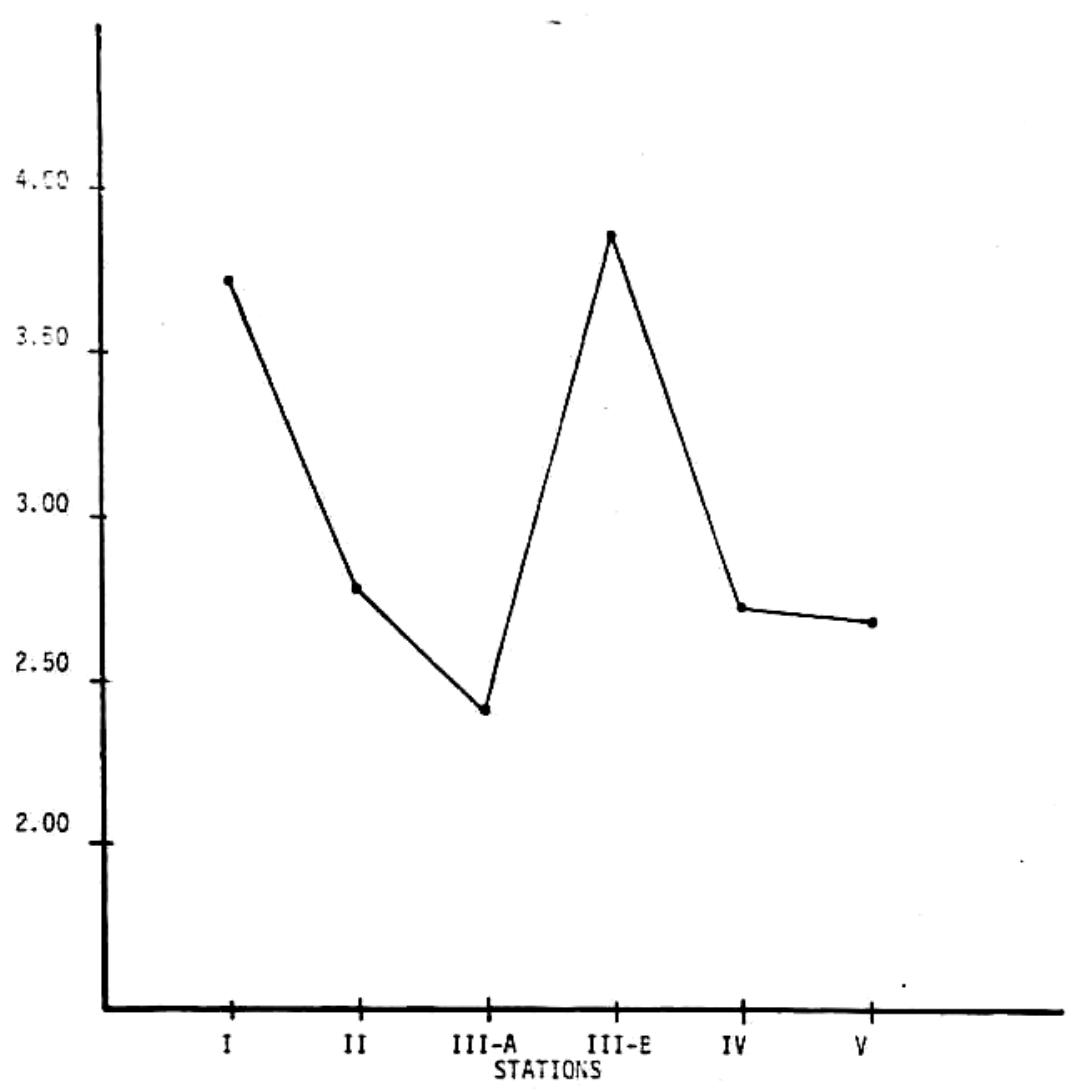

Figure 5. Shannon index of general diversity in various sub tidal stations at Napot Point and vicinity, Morong, Bataan.

Only Station 1II-B shows a variation, the number of red species being the largest, displacing the greens as the most speciose. This might be explained by the spectral quality of light at this depth which may favor the rhodophytes. Although no salinity measurements were taken, it may be inferred that Station III-B by reason of its depth and distance from shore favoring growth of rhodophytes is relatively free from fresh water which favors the growth of chlorophytes (DAWSON 1966). Lastly, the apparent stability and age of the community may indicate a near climax community which would include a greater percentage of red algae.

An inspection of the table and graph showing the distribution of animal species indicate some apparent conditions. The coelenterates, principally the scleractinian corals, are most rich at Station III-B, making up some $45 \%$ of 
the total number of species. Again, this may be correlated to depth, distance from shore and fresh water, and apparent stability or "age" (SANDERS 1969). "Age" in this case may be taken to mean the relatively undisturbed state of this community in contrast to the shallow subtidal areas which are continually subject to dynamite blasting in addition to natural disturbances caused by weather. During the sampling period, the author heard at least six blasts in the study area. If the dynamite blasting does not directly knock down coral heads, it is likely that the coral polyps are killed leading to the eventual weakening and toppling of even sizeable corals. That large corals once abounded in the area may be observed by a diver since some large, dead coral heads are evident.

Perturbations caused by weather are probably operational in at least two general ways. AlCALA (1975) has reported the destructive effects of a typhoon on corals in southern Cebu. In addition to the occasional typhoons that pass through Bataan province, the high winds of the Southwest Monsoons cause strong wave action for several months usually beginning in July. One would therefore expect the shallower areas to be subjected to high energy disturbances which would be responsible for breaking off branching corals. This alone may not explain the absence of large encrusting forms. A possible explanation related to wind energy is the stirring up of the sediments that would effectively smother coral polyps on encrusting forms such as Porites.

More likely, a related physical disturbance is responsible for the immature condition of the shallow communities. Heavy rainfall produces sediment laden run-off because of the denuded of watersheds in the area. This run-off affects the marine areas adversely in three ways. First, lowered salinity of the inshore waters is lethal to many marine organisms, especially to corals. Secondly, the sediment brought in would contribute to the smothering of sessile organisms. And thirdly, the muddy water diminishes light penetration which is detrimental to algal growth, including the symbiotic zooxanthellae in hermatypic corals.

While the molluscs are relatively speciose in Stations IV and V, they make up the largest percentage at Station II, the estuarine area. This might be expected as they have adaptations to withstand a brackishwater environment.

If similarity between stations is to be considered, Stations I and IV are closest $(S=0.42)$. These are both shallow reef areas with, rocks and sand patches. At opposite poles are Station II (estuarine) and III-B (deep coral reef) as might be expected ( $\mathrm{S}=0.18)$. Station I has much in common with all the other stations. In terms of depth and substrate, it is similar to all the 
other stations except Station III-B with which it has the least similarity ( $\mathrm{S}=$ 0.31 ). This relatively high value may be due to the proximity of the two stations being part of the same reef around Napot Point. Although one might expect Stations I and II to be dissimilar on account of the estuarine situation of the latter, Station I is the closest neighbor of Station II and one might expect migration of species between the two areas.

In terms of dominance, the highest value $(c=0.155)$ is showed by Station III-A which has a relatively small number of species represented by a large number of individuals. By contrast, Station III-B, the deep, stable, reef community shows the lowest value $(c=0.043)$. Conversely, Station III-B has the highest value for evenness, for species richness, and for the index of general diversity. As previously stated Station III-B stands out as a relatively undisturbed coral reef in contrast to all the other stations.

SLOBODKIN \& SANDERS (1969) reviewed the general principles that would support the observations made concerning Station III-B. In short, they indicated that low diversity environments fall into three general categories: 1)"new" environments, 2) "severe" environments and 3) "unpredictable" environments. By contrast with all the other areas, Station III-B is most removed from any of these three categories.

The lowest diversity is shown by Station III-A. It may be argued that there is a sampling artifact here, Station III-A being represented by only one transect. While a second transect may increase the diversity index, it is not likely that its sixth rank in terms of diversity will change principally because of the lack of a depth gradient or substrate variation.

This discussion would not be complete without a word on the use of diversity indices. While it is recognized that their use has limited value, for a comparative study such as this they have their usefulness. It is also comforting to note that besides the information presented here, the raw data and species lists of this study are recorded in the Environmental Report and will be available for future comparative studies.

\section{CONCLUSION}

This study spanned only two months and hence, the results and conclusions refer to a single season. However, it may be stated that the calm weather, dry season sampling period represented the best conditions in the year. With this background, it may be concluded that the shallow water, hard bottom communities studied were in a generally immature state. This prevalent condition appears to have resulted from physical stresses on the 


\section{EDGARDO D. GOMEZ}

ecosystem, both natural and man-caused. The area suffers by comparison with other shallow water marine communities in the Philippines which are not constantly subjected to dynamite blasting. Relatively rich and diverse reef communities may be found on may coasts. Since no comparable studies are presently available on Philippine coral communities, these statements are made from personal observations in such provinces as Zambales, Batangas, and Cebu.

It is opined that with the influx of more peace keeping forces into the Morong area dynamite blasting may disappear altogether. This will be a positive factor in the growth and recovery of the marine communities. However, the construction of the nuclear power plant will undoubtedly bring about new stresses into an already stressed environment. The initial site development will aggravate the silting problem and actually reclaim part of the shallow water areas. The long-term effects of these cannot be predicted. The more difficult question to answer is that concerning the effects of thermal effluents and possible radio-active contamination of the marine communities of Morong. Only monitoring studies and time will tell.

\section{ACKNOWLEDGEMENT}

This survey was undertaken for the National Power Corporation by the Synergistics Consultants Inc. This paper was written with the additional sponsorship of the Marine Sciences Center. The author thanks Dr. GAviNo C. Trono, JR . for the identification of the algae, Dr. ANGEL C. AlCAlA for his comments on the manuscript, and the various assistants who helped in one way or another.

\section{REFERENCES}

ALCALA, A. C. 1973. Ecosystems and ecological problems of benthic algal conservation in the Philippines, p. 32-47. In: Proceedings of the First Regional Seminar on Philippine Ecological Problems, Davao City, October 22-26, 1973, National Research Council of the Philippines.

---------1975. Biology and secondary productivity of coral reefs, p. 88-97. In: Proceedings of the Second Regional Seminar - Symposium on Biological Research Bull No. 57, June 1975. National Research Council of the Philippines.

DAWSON, E. Y. 1966. Marine Botany. Holt, Rinehart and Winston, New York, xii, 371 pp.

FAGER, E. W.; A. O. FLECHSIG; R. R. FORD; R. I. CLUTTER and R. J. GHELARDI 1966. Equipment for use in ecological studies using SCUBA. Limnol. Ocenogr. 11:503—509.

ODUM, E. P. 1971. Fundamentals of ecology. W. B. Saunders Co., Philadelphia, xiv, 574 pp. 16 


\section{SPECIES DIVERSITY OF THE EPIBENTHOS}

SANDERS H. L. 1969. Benthic marine diversity and the stability time hypothesis, p 71-81 In: Diversity and stability in ecological systems. Brookhaven Symposia in Biology No. 22.

SLOBODKIN, L. B. and H. L. SANDERS 1969. On the contribution of environmental predictability to species diversity, p. 82-95. In. Diversity and stability in ecological systems. Brookhaven .Symposia in Biology No. 22.

VELASQUEZ, G. T.; D. F. CORNEJO; A. E. SANTIAGO and L. BAENS-ARCEGA 1971 Algal commununities of exposed and protected marine waters of Batangas and Bataan. Phil. Jour. 